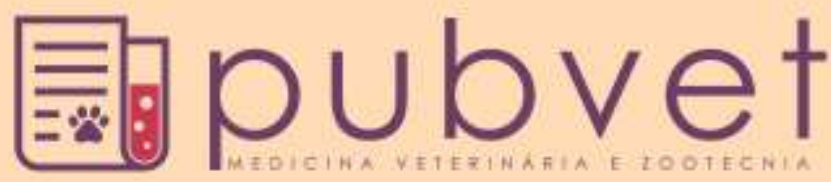

https://doi.org/10.22256/pubvet.v12n2a22.1-5

\title{
Tratamento clínico-cirúrgico de osteomielite bacteriana em Kinosternon scorpioides (Linnaeus, 1766) (Testudines, Kinosternidae): Relato de caso
}

Claudio Douglas de Oliveira Guimarães ${ }^{6} 1^{*}$, Jean Caio Figueiredo de Almeida ${ }^{6}$, Adriano Pereira Leão ${ }^{\bullet}$, Hérika Regina Vieira Santiago ${ }^{\bullet}$, Alanna do Socorro Lima da Silva ${ }^{\natural}$, André Luiz Alves de Sá ${ }^{\natural 3}$, Maridelzira Betânia Moraes David ${ }^{\natural} 1$, Maria das Dores Correia Palha ${ }^{6}$, Luiz Fernando Moraes Moreira 1

${ }^{1}$ Hospital Veterinário Mário Dias Teixeira da Universidade Federal Rural da Amazônia - UFRA, Belém Pará, Brasil

${ }^{2}$ Instituto de Biodiversidade e Florestas - Universidade Federal do Oeste do Pará - UFOPA, Santarém, Pará, Brasil.

${ }^{3}$ Projeto Bio-Fauna, Instituto Socioambiental e dos Recursos Hídricos - ISARH, Universidade Federal Rural da Amazônia -UFRA, Belém, Pará, Brasil.

*Autor para correspondência, E-mail: E-mail: cdoguimaraes@gmail.com

RESUMO. Afecções de carapaça e plastrão são comuns na medicina de quelônios e frequentemente estão associados a processos infecciosos. Este trabalho relata um caso de osteomielite em Kinosternon scorpioides, assim como o tratamento clínico cirúrgico adotado. Um espécime de $K$. scorpioides foi atendido no Hospital Veterinário da Universidade Federal Rural da Amazônia pelo setor de clínica cirúrgica cuja queixa principal era a presença de uma lesão extensa em região do plastrão. Após anamnese, exame físico, raio-x e hemograma suspeitou-se de osteomielite, sendo indicado debridamento cirúrgico. Foi coletado material da lesão para análise microbiológica e realização de antibiograma, sendo identificada a presença da bactéria Morganella morganii. Posteriormente, foi indicado tratamento com antibiótico e anti-inflamatório sistêmico, ambos por via intramuscular, além de tratamento tópico com pomada antibiótica e cicatrizante, porém, o animal veio a óbito 14 dias após o procedimento. Conclui-se que a osteomielite relatada neste estudo era de origem bacteriana, sendo indicado tratamento clínico cirúrgico. Este relato reforça a importância do acompanhamento veterinário periódico de animais silvestres cativos e contribui com novas informações sobre tratamento de afecções bacterianas nesta espécie.

Palavras chave: Microbiologia, cirurgia, quelônios, répteis

\section{Clinical-surgical treatment of bacterial osteomyelitis in Kinosternon scorpioides (Linnaeus, 1766) (Testudines, Kinosternidae): Case Report}

ABSTRACT. Carapace and plastron injuries are common in chelonian medicine and are often associated with an infectious process. This paper reports a case of osteomyelitis in Kinosternon scorpioides, as well as the surgical clinical treatment adopted. A specimen of $K$. scorpioides was attended at the Veterinary Hospital of the Federal Rural University of Amazonia by the surgical clinical sector whose main complaint was the presence of an extensive lesion in the region of the plastron. After anamnesis, physical examination, $x$-ray and hemogram were suspected of osteomyelitis, and surgical debridement was indicated. Material from the lesion was collected for microbiological analysis and antibiogram performed, and the presence of Morganella morganii bacteria was identified. 
Subsequently, treatment with antibiotic and systemic anti-inflammatory, both by intramuscular route, besides topical treatment with antibiotic ointment and cicatrizant, however, the animal came to death 14 days after the procedure. It is concluded that the osteomyelitis reported in this study was of bacterial origin, and clinical surgical treatment was indicated. This report reinforces the importance of periodic veterinary monitoring of captive wild animals and contributes with new information on the treatment of bacterial diseases in this species.

Keywords: Microbiology, surgery, chelonians, reptiles

\title{
Tratamiento clínico-quirúrgico de osteomielitis bacteriana en Kinosternon scorpioides (Linnaeus, 1766) (Testudines, Kinosternidae): Reporte de caso
}

\begin{abstract}
RESUMEN. Las afecciones de caparazón y plastrón son comunes en la medicina de los quelonios y a menudo se asocian con procesos infecciosos. Este trabajo relata un caso de osteomielitis en Kinosternon scorpioides, así como el tratamiento clínico quirúrgico adoptado. Un espécimen de $K$. scorpioides fue atendido en el Hospital Veterinario de la Universidad Federal Rural de la Amazonia por el sector de clínica quirúrgica cuya queja principal era la presencia de una lesión extensa en región del plastrón. Después de anamnesis, examen físico, radiografía y hemograma se sospechó de osteomielitis, siendo indicada la eliminación del tejido desvitalizado (método quirúrgico). Fue recogido material de la lesión para análisis microbiológica y realización de antibiograma, siendo identificada la presencia de la bacteria Morganella morganii. Posteriormente se inició tratamiento con antibiótico y antiinflamatorio sistémico, ambos por vía intramuscular, además de tratamiento tópico con pomada antibiótica y cicatrizante, pero el animal murió 14 días después del procedimiento. Se concluye que la osteomielitis relatada en este estudio era de origen bacteriano, siendo indicado tratamiento clínico quirúrgico. Este relato refuerza la importancia de la evaluación veterinaria periódica de animales silvestres cautivos y contribuye con nueva información sobre el tratamiento de las afecciones bacterianas en esta especie.
\end{abstract}

Palabras clave: Microbiología, cirugía, quelonios, reptiles

\section{Introdução}

O Kinosternon scorpioides (Linnaeus 1766) é o único quelônio pertencente à família Kinosternidae encontrado na Amazônia brasileira (Vogt et al., 2009, Berry \& Iverson, 2011). Tem como características a retração do pescoço no plano mediano formando um "S", presença de três quilhas longitudinais na carapaça e plastrão contendo duas dobradiças conferindo uma articulação entre o lobo anterior e posterior o que permite que o animal se feche total ou parcialmente dentro do casco (Cubas et al., 2014, Berry \& Iverson, 2011).

Assim como outros cágados, quando mantido em ambiente de água contaminada, o $K$. scorpioides pode desenvolver várias doenças. Entre elas, a doença cutânea ulcerativa sistêmica é a mais comum e caracteriza-se por ulcerações cutâneas, geralmente com envolvimento bacteriano e cursa com anorexia, apatia, sepse e pode culminar em óbito (Mader, 1996, Menezes, 2000, Flosi et al., 2001, Guimarães et al., 2016).

Em condições de elevada umidade, pode ocorrer o amolecimento da queratina do casco, resultando em queda das placas córneas. As regiões desprotegidas podem sofrer invasão bacteriana, o que acelera o desprendimento dos escudos da superfície óssea (Francisco, 1997). Essas bactérias são, em grande parte, oportunistas e que podem causar infecções caso as circunstâncias favoreçam, a exemplo do estudo microbiológico conduzido por Guimarães et al. (2016), o qual isolou enterobactérias a partir de abscessos em espécimes de $K$. scorpioides cativos. Levando em consideração que tão importante quanto tentar salvar a vida de um exemplar doente é procurar evitar que outros animais do plantel sejam acometidos pela mesma enfermidade (Francisco, 1997), estudos clínicos específicos se fazem necessários para elucidar o manejo e 
terapêutica de espécies cativas. Sendo assim, objetivou-se relatar um caso de osteomielite associado à infecção bacteriana em $K$. scorpioides, bem como o tratamento clínico-cirúrgico adotado.

\section{Relato de caso}

Foi atendida no Hospital Veterinário Professor Mário Dias Teixeira da Universidade Federal Rural da Amazônia, um espécime de muçuã (Kinosternon scorpioides) fêmea, adulta, proveniente do Projeto Bio-Fauna, também localizado na Instituição, pesando $0,437 \mathrm{~kg}$. A principal queixa era a presença de áreas de coloração amarelada em região do plastrão associado a descolamento de escudos córneos. De acordo com o tutor, além dessas alterações o animal apresentava perda de apetite e emagrecimento progressivo há cerca de um mês. Ao exame clínico, o animal apresentava-se apático, desidratado, desnutrido, com mucosas normocoradas e retração do globo ocular. Foi observado também que parte dos escudos córneos das placas abdominais direita e esquerda estava ausente e as placas femorais direita, esquerda e anal direita apresentavam deslocamento de parte dos escudos, caracterizado por desprendimento da placa óssea e elevação da sua superfície.

Durante a anamnese foi relatado que o animal era mantido com outros indivíduos que também apresentavam pequenas lesões na carapaça e plastrão. Todos os animais criados na mesma caixa d'água plástica com capacidade de $1000 \mathrm{~L}$ (Figura 1), dispondo de uma parte com água contendo pedras para ambientação e o restante servindo como área seca, sendo fornecida área de sombra para conforto térmico.

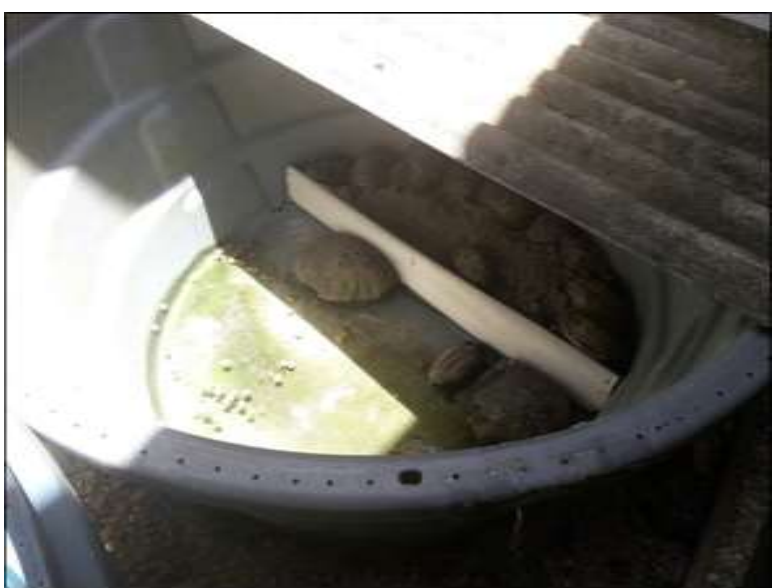

Figura 1. Recinto de manutenção dos animais.

Foi realizado exame radiográfico do paciente em projeções dorso-ventral (Figura 2) e lateral oblíqua (Figura 3) para avaliação das características, gravidade e profundidade da lesão. $\mathrm{Na}$ qual evidenciou regiões de descontinuidade nos escudos córneos abdominais e femoral esquerdo, bem como desmineralização óssea e reação periosteal em placas ósseas que compõem o hioplastrão e o hipoplastrão.

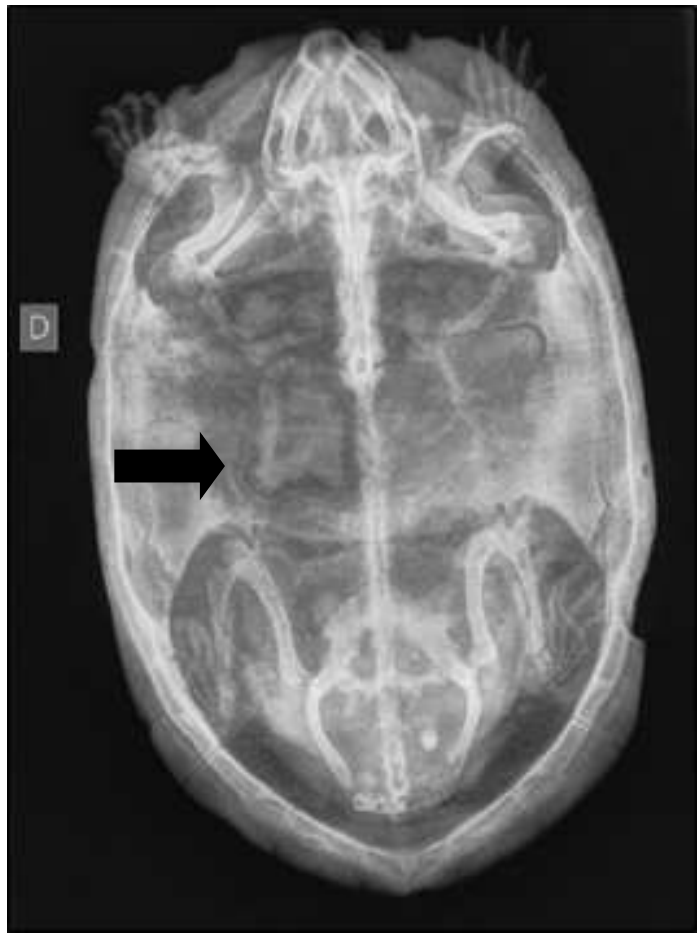

Figura 2. Radiografia do animal em projeção dorso-ventral evidenciando área de diminuição de radiopacidade (seta) em região de hioplastrão.

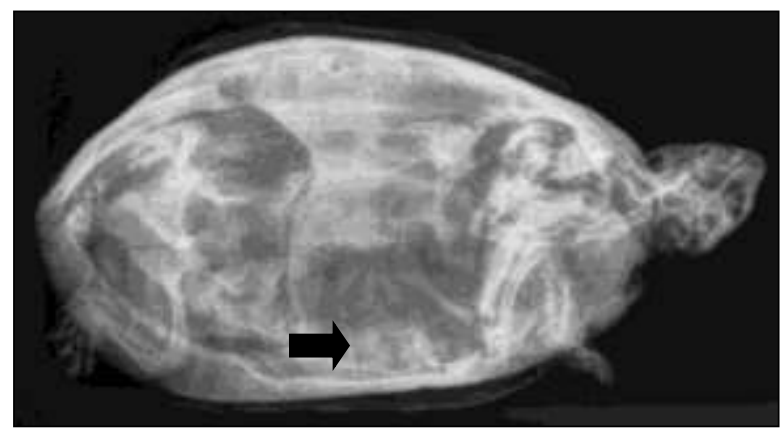

Figura 3. Radiografia do animal em projeção lateral oblíqua evidenciando área de reação periosteal (seta) em região de hioplastrão

Para realização do hemograma, foi feita coleta de sangue do seio venoso subcarapaçal utilizandose agulha hipodérmica $(25 \times 7 \mathrm{~mm})$ acoplada à seringa de $3 \mathrm{~mL}$ e cujo conteúdo foi imediatamente transferido para tubo plástico estéril contendo heparina. Após análise da amostra foi observada leucocitose $\left(31,5 \mathrm{~mm}^{3}\right)$, sendo, portanto, iniciada a terapia antibiótica com administração de enrofloxacino $2,5 \%$ na dose de $5 \mathrm{mg} / \mathrm{kg}$ por via 
intramuscular em membro anterior direito. Mediante ao quadro clínico, associado aos exames complementares, o caso foi considerado provisoriamente como laminite e osteomielite. Optou-se, portanto, pela intervenção cirúrgica imediata das lesões.

Para indução anestésica foi administrado cloridrato de quetamina $10 \%$ na dose de $40 \mathrm{mg} / \mathrm{kg}$ associado com diazepam $(50 \mathrm{mg} / \mathrm{mL})$ na dose de $1 \mathrm{mg} / \mathrm{kg}$ por via intramuscular no membro anterior esquerdo. Após sinais de miorrelaxamento e diminuição dos reflexos palpebrais, o animal foi entubado e mantido em plano anestésico com isofluorano e monitorado durante todo o transoperatório (Figura 4). Após posicionamento do paciente em decúbito dorsal, foi realizada antissepsia de toda a região do plastrão com clorexidine $2 \%$ e álcool iodado, sendo realizada retirada dos escudos córneos comprometidos e exposição da matriz óssea desmineralizada com instrumental cirúrgico estéril (Figura 5). Foi coletado material da lesão (tecido caseoso) para posterior cultura e antibiograma sendo, na sequência, realizado debridamento de todas as lesões em extensão e profundidade (Figuras 6,7 e 8). Posteriormente, foi aplicado iodopovidona e fina camada de pomada contendo nitrofurazona e colagenase por toda a área afetada (Figura 9), sendo protegida por compressa cirúrgica e fixada à carapaça com esparadrapo.

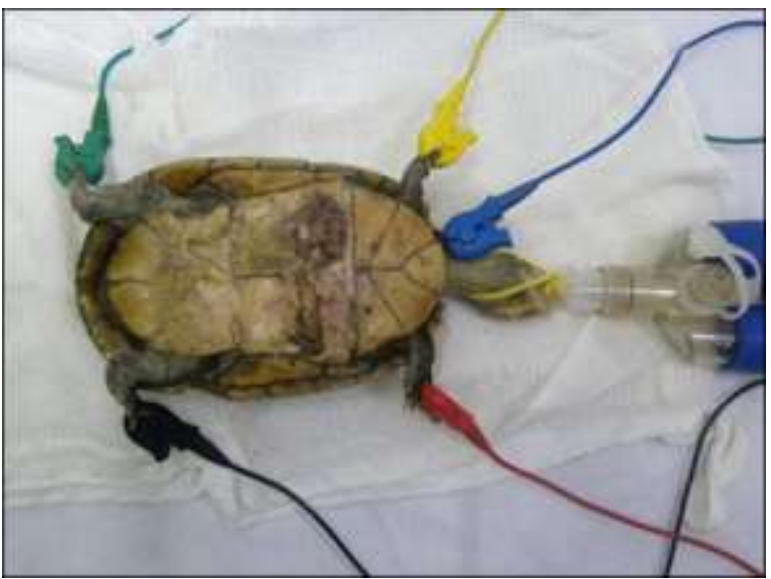

Figura 4. Paciente posicionado em decúbito dorsal, entubado e monitorado.

O paciente recuperou-se bem do procedimento cirúrgico no pós-operatório imediato e recomendou-se administração de cetoprofeno $1 \%$ na dose de $2 \mathrm{mg} / \mathrm{kg}$ e enrofloxacino $2,5 \%$ na dose de $5 \mathrm{mg} / \mathrm{kg}$, ambos a cada $48 \mathrm{hrs}$ por duas semanas. Adicionalmente, orientou-se continuar com curativos diários com pomada antibiótica e cicatrizante, mantendo o animal em isolamento durante o tratamento, com o mínimo de exposição hídrica possível.

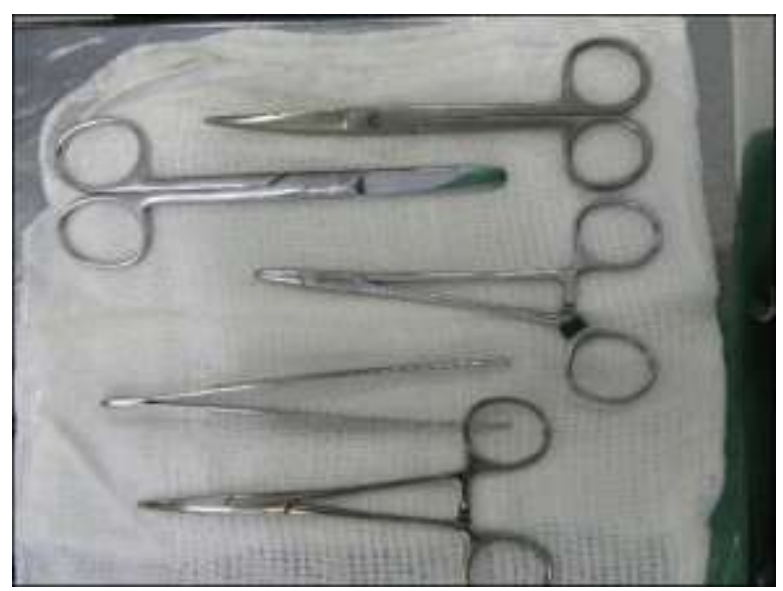

Figura 5. Instrumental cirúrgico utilizado durante o procedimento.

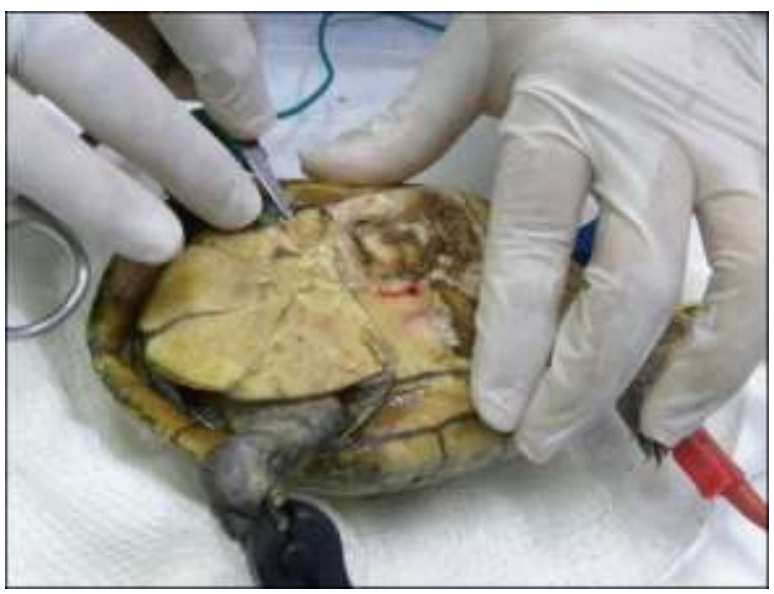

Figura 6. Início do debridamento das lesões com o auxílio de tesoura cirúrgica.

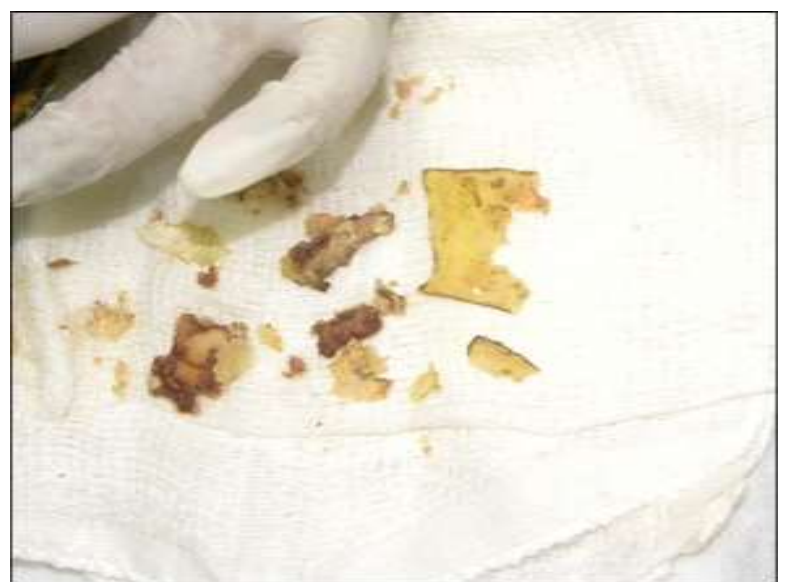

Figura 7. Parte dos escudos córneos danificados e debris teciduais retirados das lesões.

Após 10 dias do procedimento cirúrgico, o resultado da cultura bacteriana e antibiograma demonstrou a presença da bactéria Morganella morganii com sensibilidade para Amicacina, Norfloxacin e Ciprofloxacin e resistência à 
Amoxicilina + Ácido Clavulânico, Cefalotina, Cloranfenicol, Gentamicina, Norfloxacin, Rifampicim, Tetraciclina, Sulfazotrim e Azitromicina. Sendo assim, confirmou-se a suspeita diagnóstica de osteomielite bacteriana. $\mathrm{O}$ paciente veio a óbito 14 dias após a cirurgia.

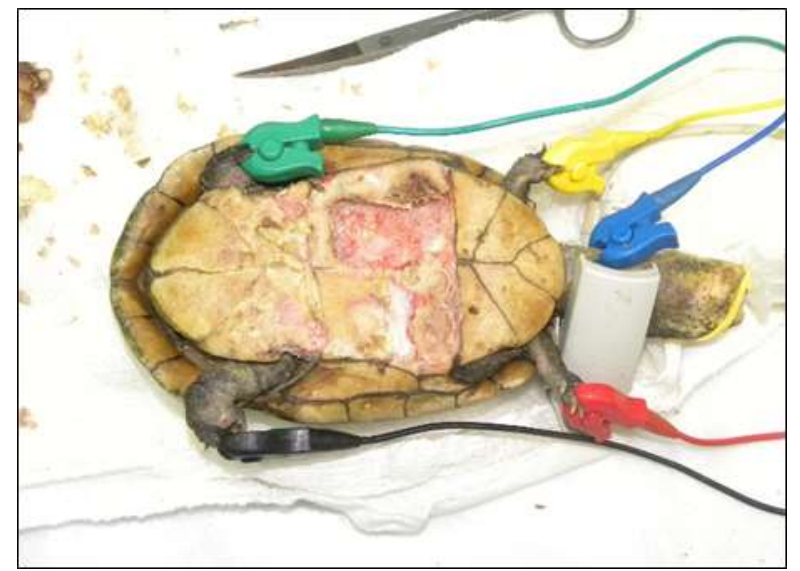

Figura 8. Aspecto do plastrão após o debridamento (notar perda de tecido ósseo).

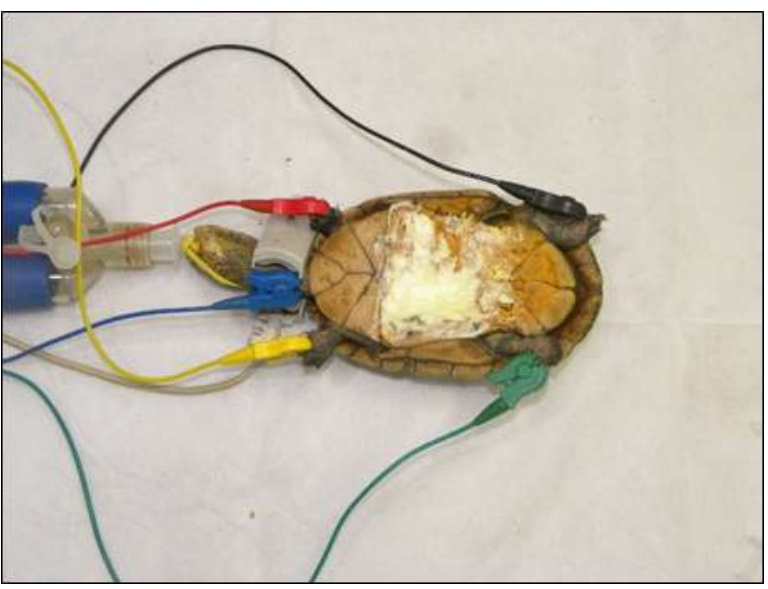

Figura 9. Lesão preenchida por pomada antibacteriana e cicatrizante.

\section{Discussão}

Sabe-se que o manejo inadequado de répteis cativos pode predispor a infecções bacterianas secundárias relacionadas principalmente à imunodepressão e ao estresse de cativeiro. Cágados, por exemplo, em ambientes de água contaminada podem desenvolver uma doença cutânea ulcerativa septicêmica causada por bactérias oportunistas que promovem o amolecimento da queratina e, caso o animal não seja convenientemente atendido, pode evoluir para hemorragias, anorexia, flacidez muscular e morte (Marcus, 1971, Francisco, 1997, Mader, 1998, Menezes, 2000). Neste estudo, o paciente era mantido em recinto com outros animais que apresentavam pequenas lesões de carapaça e do plastrão, o que pode favorecer a transmissão de patógenos intraespecífica. Demais fatores predisponentes ao surgimento dessas afecções são difíceis de identificar e ou de mensurar, devido à falta de informações sobre o manejo higiênicosanitário adotado no criadouro.

De acordo com Mader (1996) erosões e abscessos superficiais ocorrem em quelônios líminicos e são reconhecíveis como alterações da coloração dos escudos córneos, com palidez ou hiperemia, presença de lesões focais ou difusas com perda parcial ou total dos escudos afetados, sendo comum a instalação de infecção bacteriana em casco e pele nesse grupo de répteis. Estas características foram semelhantes às encontradas no presente estudo e associadas ao histórico, quadro clínico do paciente e revisão de literatura, o caso foi considerado provisoriamente como sendo uma laminite e osteomielite.

O acompanhamento radiográfico é recomendado para avaliação de lesões em carapaça e plastrão de quelônios. Além de permitir o acompanhamento do processo de cicatrização, sendo preconizadas as projeções: lateral direita e esquerda, dorso-ventral e crânio-caudal (Mader, 1996, Souza, 2006). O exame radiográfico do paciente permitiu avaliar profundidade e extensão das lesões, o que auxiliou no planejamento cirúrgico do caso, pois permitiu identificação das placas ósseas acometidas e as características de osteomielite, entre as quais desmineralização óssea e reação periosteal (Thrall, 2013).

A realização do hemograma identificou que o animal apresentava discreta leucocitose, o que fortaleceu a hipótese de que as lesões poderiam se tratar de um processo infeccioso. Como recomendado por Carpenter (2007) foi instituído o tratamento com enrofloxacino, um antibiótico frequentemente utilizado em casos de infecção de casco em quelônios e que possui amplo espectro de ação, seguindo protocolo sugerido por Carpenter (2007).

Abscessos de cascos podem se tornar profundos, com grande quantidade de debris teciduais e forte odor necrótico. Nestes casos recomenda-se curetagem e limpeza do ferimento, além de medicação tópica, sendo necessária em alguns casos sedação e/ou analgesia para conforto do paciente (Marcus, 1971, Mader, 1996). Dessa forma, o animal foi submetido ao procedimento cirúrgico de debridamento da lesão e antibioticoterapia, tal como recomendado por Avanzi \& Millefanti (2004) e Cubas et al. (2014). 
Em quelônios, quando a lesão é superficial, a queratina de revestimento se recupera de forma rápida. Porém, em lesões profundas, pode-se requerer um tempo maior de recuperação, principalmente, quando existe acometimento ósseo, podendo durar alguns meses para completa cicatrização. Para o tratamento pós-operatório foi recomendada a administração intramuscular de antibiótico e anti-inflamatório por ainda ser via mais indicada para o tratamento de répteis (Goulart, 2004), além de tratamento tópico com pomada antibiótica e cicatrizante.

Goulart (2004) afirma que o registro de microrganismos responsáveis por doenças infecciosas nos répteis é importante, pois permite a construção do perfil epidemiológico desses animais. Além disso, a realização de exames de sensibilidade bacteriana e fúngica em lesões de casco de quelônios são indicadas para direcionar o tratamento, já que existe uma escassez de estudos farmacocinéticos com essa classe medicamentosa em répteis (Marcus, 1971, Mader, 1996, Jacobson, 1999). Sendo assim, parte do material retirado da lesão e encaminhado para cultura e antibiograma identificou a presença da bactéria Morganella morgaanii, uma bactéria Gram negativa. Esta bactéria geralmente presente no ambiente e em alguns grupos de animais, entre eles mamíferos e répteis, tal como encontrado por Meyer Junior (2007), como parte da microbiota cloacal de Podocnemis expansa. Eventualmente, essa bactéria pode causar infecção em processos patológicos em répteis, como relatado por Ferreira et al. (2012) os quais isolaram M. morganii de abscessos subcutâneos em Boa constrictor. Mais recentemente, Guimarães et al. (2016) isolaram a mesma bactéria de abscessos caseosos em Kinosternon scorpioides, espécie acometida no presente relato, mostrando que esta bactéria pode ser importante na medicina desses animais.

\section{Conclusões}

$\mathrm{O}$ tratamento de infecções bacterianas em répteis ainda é pouco estudado e descrito. $\mathrm{Na}$ maioria das vezes os casos são tratados empiricamente, sem identificação dos agentes envolvidos nos processos, fato que associado à escassez de dados disponíveis sobre diagnóstico, tratamento e desfecho dos casos, dificulta a evolução do conhecimento na medicina desses animais. Sendo assim, este relato aborda informações relevantes sobre um caso de osteomielite bacteriana, bem como o tratamento clínico-cirúrgico adotado e bactéria envolvida no processo patológico. Ressalta-se que o manejo inadequado é fator preponderante no diagnóstico de doenças nesses animais, sendo imprescindível sua adequação a fim de diminuir o estresse em cativeiro.

\section{Agradecimentos}

À equipe de pesquisadores e técnicos do Projeto Bio-Fauna e do Hospital Veterinário Professor Mário Dias Teixeira da Universidade Federal Rural da Amazônia pelo apoio e disponibilização do material durante o tratamento do paciente.

\section{Referências Bibliográficas}

Avanzi, M. \& Millefanti, M. 2004. El gran libro de las tortugas acuáticas y terrestres reconocerlas, alegirlas y criarlas, Barcelona: Editorial De Vecchi.

Berry, J. F. \& Iverson, J. B. 2011. Kinosternon scorpioides (Linnaeus 1766)-Scorpion mud turtle. Chelonion Research Monographs, 5, 063.1-063.15.

Carpenter, J. W. 2007. Exotic animal formulary. 3.ed.St. Sauders: Elsevier, Louis, Missouri, USA. Saunders Elsevier, Saint Louis, Missouri, USA.

Cubas, Z. S., Silva, J. C. R. \& Dias, J. L. C. 2014. Tratado de animais selvagens-medicina veterinária. Editora Roca.

Ferreira, P. R. B., Oliveira, A. V. D., Laborda, S. S., Freire Júnior, L. J. S., Diniz, L., Queiroz, T. \& Anunciação, A. V. M. 2012. Infecção por Morganella morganii como causa de abscesso subcutâneo em Boa constrictor em conservação ex situ. Jornal Brasileiro de Ciência Animal, 5, 320-334.

Flosi, F. M., Garcia, J. M., Pugliese, C., Sanchez, A. A. \& Klai, A. 2001. Manejo e enfermidades de quelônios brasileiros no cativeiro doméstico. Revista de Educação Continuada em Medicina Veterinária e Zootecnia do $C R M V-S P, 4,65-72$.

Francisco, L. R. 1997. Répteis do Brasil, São José dos Pinhais: Amaro, Curitiba, Paraná.

Goulart, C. E. S. 2004. Herpetologia, herpetocultura e medicina de répteis, $1 \mathrm{Ed}$. edn. LF Livros, Rio de Janeiro, Brasil.

Guimarães, C. D. O., Silva, A. d. S. L., Costa, A. J. \& Palha, M. D. C. 2016. Afecções traumáticas em muçuãs (Kinosternon 
scorpioides) mantidos em cativeiro. PUBVET, 10, 001-110.

Jacobson, E. R. 1999. Use of antimicrobial drugs in reptiles. In: Fowler, M. E. \& R.E., M. (eds.) Zoo and wild animal medicine - Current therapy. Saunders, Philadelphia, USA.

Mader, D. R. 1996. Reptile Medicine and SurgeryE-Book. Elsevier Health Sciences, USA.

Mader, D. R. 1998. Common bacterial disease and antibiotic therapy in reptiles. The Compendium on Continuing Education for the Practicing Veterinarian (USA), 20, 23-33.

Marcus, L. C. 1971. Infectious diseases of reptiles. Journal of the American Veterinary Medical Association, 159, 1626-1631.

Menezes, S. R. 2000. Patologias induzidas por erros de manejo. Animal Pet, 2, 1-16.

Meyer Junior, J. C. 2007. Determinação qualitativa de enterobactérias presentes em tartarugas-da-Amazônia (Podocnemis expansa) de vida livre e cativeiro. Universidade Federal do Pará, Belém, Pará, Brasil.

Souza, R. A. M. 2006. Comparação de diferentes protocolos terapêuticos na cicatrização de carapaça de tigres-d'água (Trachemys sp.). Departamento de Veterinária. Universidade Federal do Paraná, Curitiba, Paraná.

Thrall, D. E. 2013. Textbook of veterinary diagnostic radiology. Elsevier Health Sciences, Philadelphia.

Vogt, R. C., Ferrara, C. R., Schneider, L. \& Junior, L. B. S. 2009. Brazilian Amazon turtles: habitat. Herpetological Review, 40, 213.

Angus, J. C. 2004. Otic cytology in health and disease. Veterinary Clinics of North America: Small Animal Practice, 34, 411-424.

Angus, J. C. 2005. Pathogenesis of otitis externa: understanding primary causes. Proceeding of the North American Veterinary Conference.

Birchard, S. J. \& Sherding, R. G. 2008. Manual Saunders: clínica de pequenos animais, São Paulo.

Eurides, D., Souza, L. A., Oliveira, B. J. N. A. \& Luiz, A. F. S. 2008. Drenagem de otohematoma em cães. Revista Portuguesa de Ciências Veterinárias, 103, 59-63.

Evangelista, L. S. M., Carvalho, Y. N. T., Branco, M. A. C., Lopes, R. R. F. B., Neto, J. A. \& Quessada, A. M. 2012. Estudo retrospectivo do otohematoma em cães atendidos em um hospital veterinário. Acta Veterinaria Brasilica, 6, 48-51.

Gotthelf, L. N. 2007. Doenças do ouvido em pequenos animais. Editora Roca, São Paulo.

Graça, J. C. L. 2010. Otohematoma - estudo retrospectivo de 6 anos: possíveis etiologias. Departamento de Medicina Veterinária. Universidade Técnica de Lisboa, Lisboa.

Pacheco, A., Montanha, F., Gomes, D. \& Bernardi, C. 2013. Tratamento cirúrgico de otohematoma por colocação de brinco captonado em cão-Relato de caso. Revista Científica Eletrônica de Medicina Veterinária, 20, 1-8.

Rodrigues, N. M., Quessada, A. M., Silva, F. L., Silva, E., M.C., Costa Neto, J. M. \& Lima, W. C. 2016. Epidemiologia e risco anestésico de cães portadores de otohematoma. Acta Scientiae Veterinariae, 44, 1-6.

Rosser, E. J. 2004. Causes of otitis externa. Veterinary Clinics of North America: Small Animal Practice, 34, 459-468.

Santos, S. I. R. 2008. Otohematoma canino: Epidemiologia e Terapêutica. Dissertação de Mestrado em Medicina Veterinária. Lisboa.

Schiochet, F., Teixeira, E., Rodrigues, P. R. C., Gimosk, A. W., de Castro Beck, C. A., Contesini, E. A., Alievi, M. M. \& Fratini, L. M. 2010. Hematoma auricular em gato: relato de caso. Veterinária em Foco, 7, 198-205.

Schossler, J. E., Müller, D. \& Pinheiro, M. 2007. Proposição de técnica para drenagem de Otohematoma em cães. Arquivos de Ciências Veterinárias e Zoologia da UNIPAR, 10, 117119.

Tillmann, M. T., Mendes, C. B. D. M., Felix, A. d. O. C., Mueller, E. N. \& Oliveira Nobre, M. 2014. Fibrose auricular secundária a otohematoma em felino: terapêutica com glicocorticoide- relato de caso. Science And Animal Health, 2, 42-49.

\section{Article History:}

Received 5 October 2017

Accepted 6 November 2017

Available online 28 December 2017

License information: This is an open-access article distributed under the terms of the Creative Commons Attribution License 4.0, which permits unrestricted use, distribution, and reproduction in any medium, provided the original work is properly cited. 